\title{
Assessing Employee Attitudes towards Organizational Commitment and Change: The Case of King Faisal Hospital in Al-Taif Governorate, Kingdom of Saudi Arabia
}

\author{
Wageeh A. Nafei ${ }^{1}$ \\ ${ }^{1}$ University of Sadat City, Menoufia, Egypt \\ Correspondence: Wageeh A. Nafei, University of Sadat City, Menoufia, Egypt. E-mail: \\ dr.wageeh1965@yahoo.com
}

Received: June 19, 2013

Accepted: July 22, 2013 Online Published: February 25, 2014

doi:10.5539/jms.v4n1p204

URL: http://dx.doi.org/10.5539/jms.v4n1p204

\begin{abstract}
This study investigates the attitudes of employees toward organizational commitment and change. It was conducted at King Faisal Hospital in Al-Taif Governorate, KSA. It is the first empirical work in the field of Human Resources Management aiming at analyzing the attitudes of employees toward organizational commitment and change.

The study tackles the linkage between employees' attitudes towards organizational commitment and change which is one of the most significant constructs in organizational behavior.

The present study investigates the evaluative attitudes of the employees towards organizational commitment and change. It will also illustrate the relationship between organizational commitment and change. Three groups of employees were examined. Of the 350 questionnaires that were distributed, 295 usable questionnaires were returned, a response rate of $84 \%$.

The finding reveals that there are differences among the three groups of employees regarding their evaluative attitudes towards organizational commitment and change. Also, this study showed that there is an association between organizational commitment and change. Organizational commitment is one of the important elements that have impact on organizational change. It plays an important role in employee's acceptance of change. It will result in willingness to accept organizational change. In sum, employees with high organizational commitment are more willing to exert more effort in a change project. Therefore, it is more likely to develop positive attitudes towards organizational change. Finally, the implications of this study are discussed.
\end{abstract}

Keywords: organizational commitment, organizational change

\section{Introduction}

The change can be really effective only if there is a change of attitude (Dobrea \& Găman, 2011). Change is the only constant. The only difficulty is to follow it (Bold, 2010).

Change has become a dominant aspect of organizational life (Dupuy, 2002). Change is natural and cannot be controlled. It occurs when there is economic development, climate and technology (Hatch, 2009).

One of the prerequisites of organizational change management is that for initiating and implementing successful change which is necessary to conduct a complete and systematic process for transforming the organizational realities. For that, the leadership development plays a very important role, being a key factor in the process of organizational transformation that can explain the shift from a competitive level to another one (Radu \& Năstase, 2011).

Attitudes towards organizational change may be defined as an employee's overall positive or negative evaluative judgment of a change initiative implemented by their organization (Elias, 2009). It is the internal state that influences individual's choices of personal action, or a response tendency towards the change (Bianey, et al., 2004). It is the certain regularities of an individual's feelings, thoughts and predispositions to act towards some aspect of his or her environment (Visagie, 2010). 
Organizational policies and strategies have to be changed due to the growing globalization of business, increasing competition and technological advancement (Hampel \& Martinsons, 2009).

Most challenges in organizations are generated by competition, advanced technology, mergers, expansion, product quality maintenance, enhancing employee efficiency, rapid growth, new business ventures, exciting opportunities, innovations, and new leadership and management approaches (Madsen et al., 2005). For these challenges to be overcome, employee attitudes and behaviors to accept organizational change should be taken into account for management and change agents for successful organizational change to be attained (Bernerth, 2004).

The capabilities of managers, employees and work environment are examined by organizational change that affects employee attitudes and behaviors by turning a situation from the known to the unknown. Some researchers focused on change that may have a serious negative impact on employee attitudes (Weber \& Weber, 2001). Therefore, creating employee positive attitudes boosts the readiness of employees as an important factor for successful organizational change (Rafferty \& Simon, 2006; Bareil et al., 2007).

The three factors to be considered in implementing change processes are the technological, organizational and personal perspectives. People are the most important factor in making change; however, Linstone \& Mitroff (1994) believe that they are the most difficult element to deal with.

As it involves values, preferences, and attitudes toward a particular activity human part of the organization becomes a major challenge in handling change processes in the organization. It is difficult to change attitudes as people are generally more comfortable with what they have learned or knew due to stereotyping, fear of taking risks, intolerance to ambiguity, and possibly the need to maintain tradition (Carnall, 1990). For any change to be effective, people's beliefs, and attitudes must be challenged and clarified because significant and sustainable change relies on the human system at the core of every business system (Juechter et al., 1998).

The relationship between attitudes toward organizational change, commitment, and job satisfaction have been handled by few studies (Iverson, 1996; Yousef, 2000).

The current study is trying to examine the attitudes of employees toward organizational commitment and change. The importance of the study stems from providing us with a better understanding of the relationship between organizational commitment and change as the dynamics of the business environment change rapidly. The study is structured as follows: Section one is introductory. Section two gives a theoretical construct of organizational commitment and change. Section three presents the research questions and hypotheses. Section four deals with the research methodology. Section five presents the hypotheses testing. Section six explains the research findings. Section seven presents the research recommendations. Section eight deals with the limitations and future research. Finally, section nine presents the conclusion and implications.

\section{Literature Review}

\subsection{Organizational Commitment}

Organizational commitment is widely described as a key factor in the relationship between individuals and organizations (Sharma \& Bajpai, 2010).

Mowday et al. (1982) conceive commitment as an attitude reflecting the nature and quality of the linkage between an employee and an organization. It is an individual's identification with a particular organization and its goals to maintain membership in order to attain these goals.

There are three factors of organizational commitment: (1) a strong belief in an organization's goals and values, (2) a willingness to exert considerable effort for the organization, and (3) a strong desire to maintain membership in the organization (Porter et al., 1974).

Organizational commitment is the relative strength of an individual's identification and involvement in a particular organization (Porter et al., 1976; Steer, 1977). It is an affective response which moves beyond passive loyalty to an organization. It is an attitude reflecting the nature and quality of the linkage between an employee and an organization. It is an individual's identification with a particular organization and its goals to maintain membership in order to attain these goals (Mowday et al., 1979; 1982). It is multidimensional in nature, involving an employee's loyalty to the organization, willingness to exert effort on behalf of the organization, degree of goal and value congruency with the organization, and desire to maintain membership. It refers to an employee's willingness to exert extra effort within the organization (Batemen \& Strasser, 1984). It is a feeling of dedication to one's employing organization, willingness to work hard for that employer, and the intent to remain with that organization (Meyer \& Allen, 1988). 
Organizational commitment is a feeling of dedication, willingness to go the extra mile, and an intention to stay with the organization for a long period of time. It is a multidimensional concept that provides a comprehensive insight into the link between employees and work-related behavior (Meyer \& Allen, 1991). It is the factor that promotes the attachment of the individual to the organization. To put it differently, higher levels of performance and effectiveness at both the individual and the organizational level will be the outcome of the high levels of effort exerted by employees with high levels of organizational commitment (Raju \& Srivastava, 1994).

Organizational commitment means loyalty and intention to stay with the organization, besides personal interest towards the employment (Brewer, 1996). It is the degree to which an employee feels loyal to a particular organization (Mueller et al., 1992; Price, 1997).

Organizational commitment is a critical factor in understanding and explaining the work-related behavior of employees in organizations (Lee, 2000). It is very beneficial for the organization as it reduces the absenteeism rate and turns over ratio, let alone enhancing the organization's productivity (Jernigan et al., 2002). It is interested in the employee's willingness to leave their organization (Greenberg \& Baron, 2003). The employee who is highly committed to the organization contributes to the organization performance (Freund \& Carmeli, 2003). It reflects the work attitudes of employees toward the organizations in which they work (Silverthorne, 2004).

Organizational commitment is very important because it is linked with absenteeism, work effort and turnover (Joiner \& Bakalis, 2006). It is concerned with the extent to which an employee identifies with the organization. It is an individual's willingness to dedicate efforts and loyalty to an organization (Jalonen, et al., 2006; Wagner, 2007). It is described as a key factor in the relationship between individuals and organizations (Sharma \& Bajpai, 2010).

The three components conceptualization of organizational commitment indicated by Meyer and Allen $(1991 ; 1993)$ are as follows:

- Affective commitment refers to the sense of affection and feelings of attachment to the organization and has been associated with work experiences, individual traits and organizational structures.

- Continuance commitment refers to consciousness of the costs related to parting with the organization or job. Employees with elevated level of continuance commitment stay with the organization as they are aware of the need, risks, sacrifices, and low options associated with leaving.

- Normative commitment refers to a sense of requirement to continue employment. Employees with elevated level of normative commitment believe that they have to remain in the organization or job as they feel it is right. Normative commitment is the level to which a person is psychologically associated with the organization through internalization of its vision, goals, objectives, principles, values and missions.

Employees can experience all three forms of commitment. The psychological states reflecting the three components of organizational commitment will develop as the function of quite different antecedents. They will also have different implications for work behavior. Most managers would agree that it is very difficult to find employees who have both high levels of task performance and organizational commitment (Meyer \& Allen, 1991).

\subsection{Organizational Change}

Change is the process of analyzing the past to elicit the present actions required for the future (Kanter et al., 1992). Change variables may be defined in a series of interrelating elements (actions, reactions and interactions) (Soparnot, 2011).

Organizational change is at the forefront of the academic and managerial environment (Pettigrew et al., 2001). It showed a diversity of the organization in its environment, and also the interaction of the technical and human activities that had interrelated dimensions in the organization (Cao et al., 2000).

It is important to mention that many organizations deal with organizational change on a regular basis. A case in point is how Yahoo's CEO (i.e., Marissa Mayer) recently decided to change and ban the telecommuting policy. "Organizations are goal-oriented, purposive entities, and their effectiveness is pursuing those goals influences the quality of our lives and even our ability to survive" (Rainey, 2003).

This unexpected change will create many cynics who do not agree with its decision and feel disrespected. A leader should know that, "Respect is not something one can imitate, but something one must embody" (Lawrence-Lightfoot, 2000).

As such, managers should consider consulting with employees during such drastic changes. "Learning to understand and see things from another's perspective is absolutely crucial to building trusting relations and to career success" (Kouzes, 2003). 
Some organizational changes are necessary in order for the organization to compete with its competitors. For example, many hospitals made a significant change from using analog x-rays to digital images. Kaifi (2010) explains, "Technological advancements have allowed for digital images (x-rays) to be analyzed by medical doctors (radiologists) outside of the U.S. As a result, radiologists in the US have become cynical". Thus, managers are expected to formulate and implement meaningful changes to the organization that complement the organization's culture.

Khademian (2002) explains, "Determining what needs to be changed and articulating those changes is an essential part of the effort to manage the integration of cultural roots. If managers want to change how the job gets done, they must understand the commitments driving the work of the program and how those commitments might need to change. Articulating those changes helps participants to see the task, the resources, and the skills they bring to the table, and the environment in which they work, differently". Organizational change can be a stressful time for employees for a number of reasons ranging from learning a new task to jobs being eliminated. As such, some employees are more resistant to change while others are more receptive to change.

There are three types of individuals' or groups' response to organizational change. They are affective, cognitive and instrumental. Affective response refers to the feeling of being linked to satisfaction or anxiety about change. Cognitive responses are opinions relating to usefulness and necessity and about knowledge required to handle change. Instrumental responses refers to actions already taken or which will be taken to handle the change (Elizur \& Guttman, 1976).

Dunham et al. (1989) suggested that there are three types of attitudes toward change; affective, cognitive and behavioral.

- The cognitive component of an attitude consists of the information a person possesses about a person or thing which is based on what a person believes to be true.

- The affective component consists of the feelings a person has toward an attitude object, which involves evaluation and emotion, and is often expressed as like or dislike for the attitude object.

- The behavioral tendency concerns the way a person intends to behave toward an attitude object.

The three types of attitudes are more critical. Organizational changes should start by the cognitive, affective, and the behavioral mode. The cognitive mode can be an effective mode to be addressed first. This is because once a person has information and knowledge of the potential changes to be made, his or her feelings toward change may be changed to favor such changes. It should be highlighted that handling the cognitive component on attitude toward change can be a daunting task if it is not well communicated. This will be demonstrated by the behavioral mode of the person in responding to the changes.

\subsection{Organizational Commitment and Change}

Organizational commitment is one of the important elements that have impact on organizational change. Meyer \& Allen (1997) assert that employees of high affective commitment demonstrate emotional attachment and identification with their involvement in the organization. This may explain why these employees are less likely to engage in withdrawal behavior and are more willing to accept change (Somers, 1995). If employees are committed to making it work, organizational change can be successful. It is best when it is based upon a belief in the value of the initiative and employees wanting to see it succeed (Meyer \& Allen, 1997).

Organizational commitment plays an important role in employee's acceptance of change (Darwish, 2000). Guest (1987) argued that the total causal effects of positive affectivity, job security, job satisfaction, job motivation and organizational change are mediated organizational commitment.

Also, Guest (1997) suggests that organizational commitment will result in willingness to accept organizational change. In sum, a greater degree of organizational commitment should lead to successful organizational readiness for a change process. Therefore, it is suggested that a positive relationship exist among leadership behavior, organizational commitment and emotional intelligence on organizational readiness for change.

Some researches believe that attitudes to organizational change might be influenced by organizational commitment. But other studies indicated that, within a change context, organizational commitment is a better predictor of behavioral intentions than job satisfaction (Iverson \& Roy, 1994).

The other researchers argued that a highly committed employee is more willing to accept organizational change if it is perceived to be beneficial. But Lau \& Woodman (1995) argue that they may resist change if he/she perceives it as a threat for his/her own benefit. 
Iverson (1996) found that an employees' acceptance of organizational change increases with organizational commitment. The employee's acceptance decreases with union membership, role conflict, tenure and environmental opportunity. Organizational commitment is the most important determinant of attitudes toward organizational change. In other words, employees with high organizational commitment are more willing to exert more effort in a change project and, therefore, it is more likely to develop positive attitudes towards organizational change. Organizational commitment influence certain attitudes toward organizational change, and job satisfaction with certain facets of job directly and indirectly influences the different dimension of attitudes toward organizational change (Yousef, 2000).

The present study of organizational change is of interest to a large number of researchers. Many studies on organizational commitment have been conducted, but not specifically addressed to the relations of organizational change among employees at King Faisal Hospital in Al-Taif Governorate, KSA. This reveals the importance of the present study, theoretically and practically, as it determines the dimensions of organizational commitment and organizational change.

\section{Research Questions and Hypotheses}

Organizational change has been one of the widely researched areas in the field of management but at King Faisal Hospital in Al-Taif Governorate, KSA Hospitals very few studies have explored this concept. The objective of this study is to analyze the attitudes of employees toward organizational commitment and its relation with their organizational change at King Faisal Hospital in Al-Taif Governorate, KSA.

The research question or hypothesis is a key preliminary step in the research process. The research question presents the idea that is to be examined in the study. It is the foundation of the research study. The hypothesis attempts to answer the research question. This research aims at answering the following questions:

Q1: Are there fundamental variations among the employees at King Faisal Hospital in Al-Taif Governorate, KSA towards organizational commitment?.

Q2: Are there fundamental variations among the employees at King Faisal Hospital in Al-Taif Governorate, KSA towards organizational change?.

Q3: What is the relationship between organizational commitment (the affective component, the cognitive component, the behavioral tendency) and organizational change at King Faisal Hospital in Al-Taif Governorate, KSA?.

From the above-mentioned research questions, this study attempts to test the following hypotheses:

H1: There is no significant discrimination among the employees at King Faisal Hospital in Al-Taif Governorate, KSA towards organizational commitment.

H2: There is no significant discrimination among the employees at King Faisal Hospital in Al-Taif Governorate, KSA towards organizational change.

H3: There is no statistically significant relationship between organizational commitment (the affective component, the cognitive component, the behavioral tendency) and organizational change at King Faisal Hospital in Al-Taif Governorate, KSA.

\section{Methodology and Research Design}

\subsection{Participants and Procedures}

This study investigates the attitudes of employees toward organizational commitment and change. It was conducted at King Faisal Hospital in Al-Taif Governorate, KSA. This is why the population under study involves all categories of employees (physicians, nurses, administrative staff). This hospital has been chosen for applying the field study as it is one of the biggest governmental hospital in Al-Taif Governorate. It cost 550 million riyals for construction, while its capacity amounts to 500 beds. It involves all medical and remedial specializations, along with developed medical cadres who work at this gigantic hospital. The most important specializations include intensive care, surgery, internal medicine, newborns, radiology, pharmacy, laboratory, incubators, etc. The medical and health services provided by this hospital are equal to those of the developed major hospitals in KSA (Planning Administration, King Faisal Hospital in Al-Taif, 2012).

Three hundred and fifty employees were randomly selected from the different categories of employees at King Faisal Hospital in Al-Taif Governorate, KSA. To ensure anonymity, they were asked not to put any form of identification on the questionnaire. The study questionnaire containing measures of organizational change and organizational commitment was distributed to employees using the drop-off method. 
The questionnaire included three pages following the introductory page explaining the aims of the study. Next come guided and direct questions. In this way, the probabilities of bias in data collection are reduced. Only 25 questionnaires were piloted by a closed circle of employees, requiring some modification. Data collection was accomplished through contacting informants in informal interviews. Each informant was given a list of questions and enough time to answer them.

The questionnaire included three types of questions, relating to recognizing organizational commitment, organizational change, and the demographic variables of employees at King Faisal Hospital in Al-Taif Governorate, KSA. Data collection took approximately two months. Overall, 295 respondents completed the questionnaire, for a response rate of $84 \%$.

About $39 \%$ of the participants were physicians, $52 \%$ nurses, and $10 \%$ administrative staff. With respect to gender, $42 \%$ were male and $58 \%$ were female. About $27 \%$ of the participants were single and $73 \%$ were married. As for age, $43 \%$ of the participants were under 30 years old, $37 \%$ ranged from 30 to 45 years old, and above 45 years old were $20 \%$. Concerning the educational level, holders of the secondary school certificate amounted to $23 \%$, university education $59 \%$ and Master or PhD degree $19 \%$. Regarding the period of experience, $40 \%$ of the participants were less than five years, $23 \%$ ranged from 5 to 10 years, and more than 10 years were $38 \%$.

\subsection{Measures}

\subsubsection{Organizational Commitment}

Aspects of organizational commitment include affective, continuance, and normative commitment. The researcher has employed the measure developed by Allan and Meyer, 1990, modified by Meyer et al., 1993, to measure organizational commitment. This measure consists of 18 statements; six statements for each secondary measure. A Likert-type scale has been used for gauging levels of agreement and/or disagreement. It is composed of five degrees, (5) refers to full agreement, while (1) refers to full disagreement and neutral degrees are found in between. This measure is used in many studies like Meyer et al., 1993 and Dunham et al., 1994.

\subsubsection{Organizational Change}

The researcher has drawn on the scale of Dunham et al., (1989), Lussier (1990), and Kursunoglu \& Tanriogen (2009) for measuring organizational change. Attitudes towards changes in the model are divided into three dimensions, namely cognitive, affective and behavioral. The cognitive dimension of meaning in terms of changing views on the advantages and disadvantages, benefits, requirements, knowledge needed to manage change. The affective dimension refers to feelings associated with dissatisfaction and concern in making the changes. The dimensional behavior is the action taken or to be taken in future in the face of change or resist change. This measure consists of 18 statements equally divided among secondary measures. A Likert scale was used for judging levels of agreement or disagreement, ranging from (5) which refers to full agreement and (1) which refers to full disagreement. The informant should select the answer that suits his choice, where (5) indicates full agreement while (1) indicates full disagreement, with neutral degrees in- between.

\subsection{Method of Data Analysis and Testing Hypotheses}

The researcher has employed the following methods (1) the Alpha Correlation Coefficient (ACC or Cronbach's alpha), (2) Multiple Discriminant Analysis (MDA), (3) Multiple Regression Analysis (MRA), and (4) the statistical testing of hypotheses which includes Wilk's Lambda and chi-square that goes hand in hand with the MDA and F-test and T-test which go hand in hand with the MRA.

\section{Hypotheses Testing}

\subsection{Evaluating Reliability}

The reliability of organizational commitment and organizational change was assessed to reduce errors of measuring and maximizing constancy of these scales.

ACC (Cronbach's alpha) was used to determine the degree of internal consistency among the contents of the scale under testing. It was decided to exclude variables that had a correlation coefficient of less than 0.30 when the acceptable limits of ACC (Cronbach's alpha) range from 0.60 to 0.80 (Nunnally \& Bernstein, 1994). Levels of reliability analysis in social sciences so decide. 
Table 1. Reliability of organizational commitment

\begin{tabular}{lll}
\hline $\begin{array}{l}\text { The Dimension of } \\
\text { Organizational Commitment }\end{array}$ & Number of Statement & ACC (Cronbach's alpha) \\
\hline Affective Commitment & 6 & 0.859 \\
Continuance Commitment & 6 & 0.803 \\
Normative Commitment & 6 & 0.838 \\
Total Measurement & $\mathbf{1 8}$ & $\mathbf{0 . 8 7 7}$ \\
\hline
\end{tabular}

According to Table (1) the internal consistency or reliability of the preferred organizational commitment scales ranges from 0.83 to 0.85 . As a result, the overall reliability of the preferred organizational questionnaire is 0.88 , giving evidence of reliability of the organizational commitment scale.

Table 2. Reliability of organizational change

\begin{tabular}{lll}
\hline $\begin{array}{l}\text { The Dimension of } \\
\text { Organizational Change }\end{array}$ & Number of Statement & ACC (Cronbach's alpha) \\
\hline The Cognitive Dimension & 6 & 0.817 \\
The Affective Dimension & 6 & 0.730 \\
The Behavioral Dimension & 6 & 0.807 \\
Total Measurement & $\mathbf{1 8}$ & $\mathbf{0 . 7 9 5}$ \\
\hline
\end{tabular}

Table (2) presents the internal consistency or reliability of the scales measured through Cronbach's alpha. The reliabilities of the affective and cognitive scales are generally higher (ranging from 0.73 to 0.82 ); while the behavioral scale is at 0.81 , still indicating high reliability. The overall reliability of the preferred organizational questionnaire is 0.79 , proving that organizational change scale is reliable.

\subsection{Organizational Commitment}

The statistical results for the evaluative attitudes of employees towards organizational commitment are studied. The second hypothesis to be tested is:

H1: There is no discrimination among the employees at King Faisal Hospital in Al-Taif Governorate, KSA towards organizational commitment.

The MDA was applied on three groups of employees regarding their evaluative attitudes towards organizational commitment as presented in Tables (3) and (4).

Table 3. Multiple discriminant analysis of organizational commitment

\begin{tabular}{|c|c|c|c|c|c|c|c|c|}
\hline \multicolumn{9}{|c|}{ A- Discriminant Functions (DF) } \\
\hline Function & $\begin{array}{l}\text { Eigen } \\
\text { Values }\end{array}$ & $\begin{array}{l}\text { The } \% \text { of } \\
\text { Differences }\end{array}$ & $\mathrm{MCC}$ & $\begin{array}{l}\text { Wilks } \\
\text { Lambada }\end{array}$ & $\begin{array}{l}\text { Ch-Squar } \\
\mathrm{e}\end{array}$ & \multicolumn{2}{|c|}{$\begin{array}{l}\text { Degree of } \\
\text { Sign } \\
\end{array}$} & $\begin{array}{l}\text { Level of } \\
\text { Sign } \\
\end{array}$ \\
\hline 1 & 0.183 & 64.0 & 0.394 & 0.766 & 76.89 & 16 & & 0.000 \\
\hline 2 & 0.103 & 36.0 & 0.306 & 0.906 & 28.33 & 7 & & 0.000 \\
\hline \multicolumn{9}{|c|}{ B- Classification Matrix } \\
\hline \multicolumn{2}{|l|}{ Groups } & Number & \multicolumn{2}{|c|}{ Predict Member of Groups } & & & \multicolumn{2}{|c|}{ Total } \\
\hline Physicians & & 114 & $\begin{array}{l}56 \\
(49.1 \%)\end{array}$ & $\begin{array}{l}37 \\
(32.5 \%)\end{array}$ & \multicolumn{2}{|c|}{$\begin{array}{l}21 \\
(18.4 \%)\end{array}$} & \multicolumn{2}{|l|}{114} \\
\hline \multicolumn{2}{|l|}{ Nurses } & 151 & $\begin{array}{l}56 \\
(37.1 \%)\end{array}$ & $\begin{array}{l}75 \\
(19.7 \%)\end{array}$ & \multicolumn{2}{|c|}{$\begin{array}{l}20 \\
(13.2 \%)\end{array}$} & \multicolumn{2}{|l|}{151} \\
\hline \multicolumn{2}{|c|}{ Administrative Staff } & 30 & \multirow[t]{2}{*}{$\begin{array}{l}5 \\
(16.7 \%)\end{array}$} & \multirow[t]{2}{*}{$\begin{array}{l}7 \\
(23.3 \%)\end{array}$} & \multicolumn{2}{|c|}{$\begin{array}{l}18 \\
(60.0 \%)\end{array}$} & 30 & \\
\hline Total & & 295 & & & & & 295 & \\
\hline \multicolumn{4}{|c|}{ The Percentage of the exact division } & \multicolumn{5}{|c|}{$50.0 \%$} \\
\hline
\end{tabular}


According to MDA, the most important findings include the following:

1) There is a high degree of difference among attitudes of employees towards organizational commitment (the percentage of differentiation was $64 \%$ ).

2) There is a strong significant relationship (MCC represents 0.39 ) and a statistically significant relationship at level 0.01 between healthcare organizations of the employees groups and their evaluative attitudes towards organizational commitment.

3) The accurate classification of employees according to their evaluative attitudes towards organizational commitment is $50 \%$. The rest, $50 \%$, are similar.

4) There are eight variables relating to organizational commitment. They have an ability to discriminate among employees (see Table 4). The most important of them are "lack of work opportunities at other places is one of the most important reasons behind my remaining at this hospital" (discrimination coefficients represent 0.57), "this hospital deserves my full interest and loyalty" (discrimination coefficients represent 0.50 ), "I will not leave this hospital now as I feel I have duty towards its members" (discrimination coefficients represent 0.49 ), "I feel emotional relation to the hospital where I work" (discrimination coefficients represent 0.47), "I feel I am a member of the family of this hospital" (discrimination coefficients represent 0.46 ), "I think every person should keep his or her loyalty to the hospital" (discrimination coefficients represent 0.45 ), and "I feel strong loyalty and belonging to the family of this hospital" (discrimination coefficients represent 0.32 ).

Table 4. The mean of employees towards organizational commitment

\begin{tabular}{|c|c|c|c|c|c|}
\hline \multirow[b]{2}{*}{ The Variables } & \multicolumn{3}{|l|}{ Mean } & \multirow[b]{2}{*}{ F-Test } & \multirow[b]{2}{*}{$\begin{array}{l}\text { Level } \\
\text { of Sig }\end{array}$} \\
\hline & $\begin{array}{l}\text { Group } \\
1\end{array}$ & $\begin{array}{l}\text { Group } \\
2\end{array}$ & $\begin{array}{l}\text { Group } \\
3\end{array}$ & & \\
\hline $\begin{array}{l}\text { Lack of work opportunities at other places is one of the } \\
\text { most important reasons behind my remaining at this } \\
\text { hospital. }\end{array}$ & 2.89 & 3.41 & 3.30 & $5.048^{* *}$ & 0.575 \\
\hline This hospital deserves my full interest and loyalty. & 3.59 & 3.98 & 3.66 & $4.061^{*}$ & 0.502 \\
\hline $\begin{array}{l}\text { I will not leave this hospital now as I feel I have duty } \\
\text { towards its members. }\end{array}$ & 3.32 & 3.70 & 3.43 & $3.694^{*}$ & 0.486 \\
\hline I feel emotional relation to the hospital where I work. & 3.44 & 3.79 & 4.26 & $7.595^{* *}$ & 0.473 \\
\hline I feel I am a member of the family of this hospital. & 3.59 & 3.73 & 4.36 & $6.290^{* *}$ & 0.461 \\
\hline $\begin{array}{l}\text { I think every person should keep his or her loyalty to the } \\
\text { hospital. }\end{array}$ & 3.95 & 4.20 & 4.60 & $7.875^{* *}$ & 0.450 \\
\hline $\begin{array}{l}\text { I feel strong loyalty and belonging to the family of this } \\
\text { hospital. }\end{array}$ & 3.64 & 3.88 & 3.76 & 1.586 & 0.324 \\
\hline $\begin{array}{l}\text { It is very difficult for me to leave work at the hospital, even } \\
\text { if I want so. }\end{array}$ & 3.54 & 3.50 & 3.73 & 0.470 & 0.129 \\
\hline
\end{tabular}

According to the mean of the three groups of employees (see Table 4), it was revealed that there are differences among them. As for physicians, they tend to agree, for example, that "I think every person should keep his or her loyalty to the hospital" (with a mean of 3.95), "I feel strong loyalty and belonging to the family of this hospital" (with a mean of 3.64), "this hospital deserves my full interest and loyalty" (with a mean of 3.59), "I feel I am a member of the family of this hospital" (with a mean of 3.59), "it is very difficult for me to leave work at the hospital, even if I want so" (with a mean of 3.54), and "I feel emotional relation to the hospital where I work" (with a mean of 3.44). As for nurses, they tend to agree, for example, that "I think every person should keep his or her loyalty to the hospital" (with a mean of 4.20), "this hospital deserves my full interest and loyalty" (with a mean of 3.98), "I feel strong loyalty and belonging to the family of this hospital" (with a mean of 3.88), "I feel emotional relation to the hospital where I work" (with a mean of 3.79), "I feel I am a member of the family of this hospital" (with a mean of 3.73), "I will not leave this hospital now as I feel I have duty towards its members" (with a mean of 3.70), and "it is very difficult for me to leave work at the hospital, even if I want so" (with a mean of 3.50). As for administrative staff, they tend to agree to a high degree, for example, that "I think every person should keep his or her loyalty to the hospital" (with a mean of 4.60), "I feel I am a member of the family of this hospital" (with a mean of 4.36), "I feel emotional relation to the hospital where I work" (with a mean of 4.26), "I feel strong loyalty and belonging to the family of this hospital" (with a mean of 3.76), "it is 
very difficult for me to leave work at the hospital, even if I want so" (with a mean of 3.73), "this hospital deserves my full interest and loyalty" (with a mean of 3.66), and "I will not leave this hospital now as I feel I have duty towards its members" (with a mean of 3.43).

Accordingly, the null hypothesis is rejected because the value of Wilks Lambda in the MDA amounts to 0.76 (see table 3). Moreover, the value of chi-square calculated (76.89) in the free degree of (16) exceeds its table counterpart (42.98) at the level of statistical significance of 0.01 (see table 3). Furthermore, it was decided to reject the same null hypothesis of eight variables of organizational commitment (13 variables) taken individually at the statistical significance level of 0.01 , according to the test of univariate F. (see table 4).

\subsection{Organizational Change}

The statistical results for the evaluative attitudes of employees towards organizational change are judged. The first hypothesis to be tested is:

\section{H2: There is no discrimination among the employees at King Faisal Hospital in Al-Taif Governorate, KSA regarding organizational change.}

The MDA was applied on a model including three groups of employees and their evaluative attitudes towards organizational change as displayed in Tables (5) and (6).

Table 5. Multiple discriminant analysis of organizational change

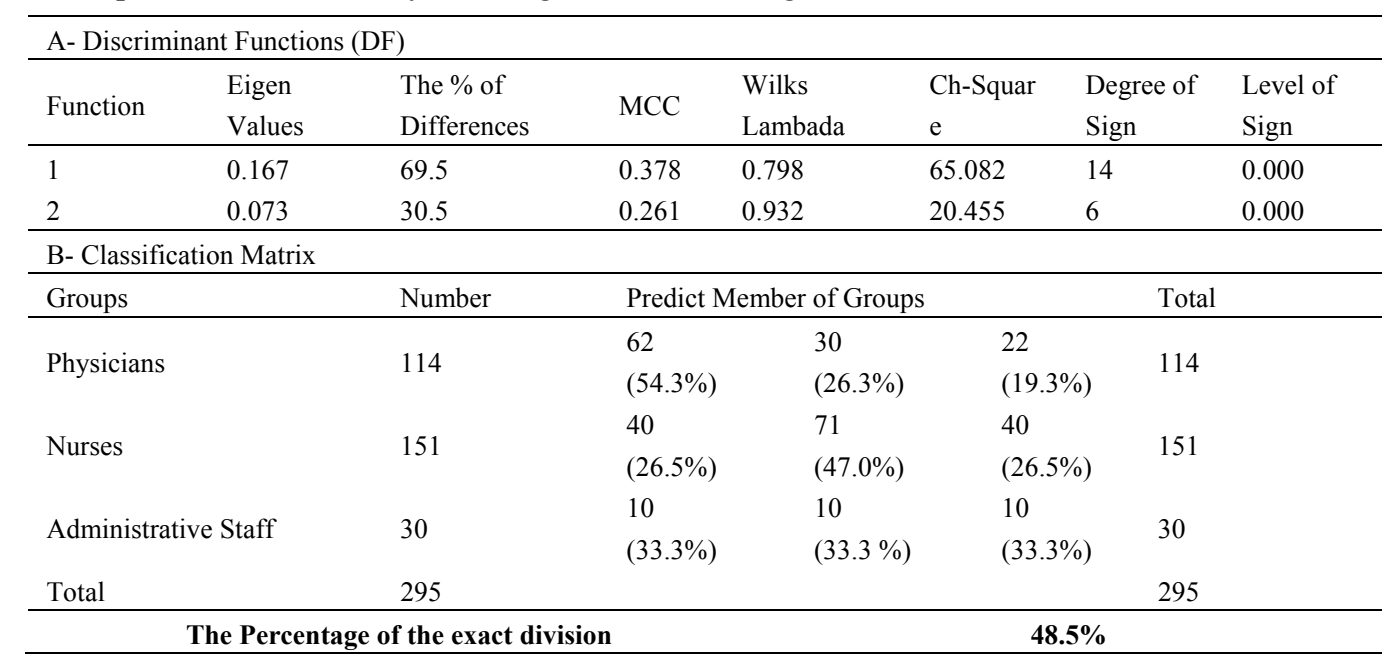

According to MDA, the most important findings include the following:

1) There is a high degree of difference among attitudes of employees towards organizational change (the percentage of differentiation was $69 \%$ ).

2) There are a strong significant relationship (MCC represents 0.37 ) and a statistically significant relationship at level 0.01 between healthcare organizations of the employees groups and their evaluative attitudes towards organizational change.

3) The accurate classification of employees according to their evaluative attitudes towards organizational change is $48.5 \%$. The rest, $51.5 \%$, are similar.

4) There are seven variables relating to organizational change. They can discriminate among employees (see Table 6), most importantly "I usually take advantage of the change in the hospital" (discrimination coefficients represent 0.67 ), "most of the changes in the hospital bother me" (discrimination coefficients represent 0.65 ), "I usually hesitate to try any new ideas in the hospital" (discrimination coefficients represent 0.52 ), "change in the work environment reduces my ability to control what is going on around me in the hospital" (discrimination coefficients represent 0.50 ), "I'm looking forward to the change happening in my field in the hospital" (discrimination coefficients represent 0.42 ), "I intend to do everything in my power to support change in the hospital" (discrimination coefficients represent 0.32 ), and "change usually benefits the hospital" (discrimination coefficients represent 0.31 ). 
Table 6. The mean of employees towards organizational change

\begin{tabular}{|c|c|c|c|c|c|}
\hline \multirow[t]{3}{*}{ The Variables } & \multicolumn{3}{|l|}{ Mean } & \multirow[t]{3}{*}{ F-Test } & \multirow{3}{*}{$\begin{array}{l}\text { Level } \\
\text { of Sig }\end{array}$} \\
\hline & Group & Group & Group & & \\
\hline & 1 & 2 & 3 & & \\
\hline I usually take advantage of the change in the hospital. & 3.36 & 3.39 & 2.73 & $4.871^{* *}$ & 0.671 \\
\hline Most of the changes in the hospital bother me. & 2.60 & 2.55 & 3.30 & $4.548^{*}$ & 0.650 \\
\hline I usually hesitate to try any new ideas in the hospital. & 2.47 & 2.96 & 3.26 & $8.067^{* *}$ & 0.523 \\
\hline $\begin{array}{l}\text { Change in the work environment reduces my ability to } \\
\text { control what is going on around me in the hospital. }\end{array}$ & 3.28 & 2.98 & 3.60 & $3.874^{*}$ & 0.501 \\
\hline $\begin{array}{l}\text { I'm looking forward to the change happening in my field } \\
\text { in the hospital. }\end{array}$ & 4.23 & 3.90 & 3.86 & $4.377^{*}$ & 0.418 \\
\hline $\begin{array}{l}\text { I intend to do everything in my power to support change } \\
\text { in the hospital. }\end{array}$ & 3.89 & 4.13 & 4.13 & 2.517 & 0.320 \\
\hline Change usually benefits the hospital. & 3.56 & 3.84 & 3.56 & $3.051^{*}$ & 0.309 \\
\hline
\end{tabular}

According to the mean of the three groups of employees (see Table 6), differences among them emerged. As for physicians, they tend to agree, for example, that "I'm looking forward to the change happening in my field in the hospital" (with a mean of 4.23), "I intend to do everything in my power to support change in the hospital" (with a mean of 3.89), and "change usually benefits the hospital" (with a mean of 3.56). As for nurses, they tend to agree, for example, that "I intend to do everything in my power to support change in the hospital" (with a mean of 4.13), "I'm looking forward to the change happening in my field in the hospital" (with a mean of 3.90), and "change usually benefits the hospital" (with a mean of 3.84). As for administrative staff, they tend to agree to a high degree, for example, that "I intend to do everything in my power to support change in the hospital" (with a mean of 4.13), "I'm looking forward to the change happening in my field in the hospital" (with a mean of 3.86), and "change in the work environment reduces my ability to control what is going on around me in the hospital" (with a mean of 3.60).

Accordingly, the null hypothesis is rejected because of the value of Wilks Lambda in the MDA amount to 0.79 (see table 5). Besides the value of chi-square calculated (65.08) in the free degree of (14) exceeds its table counterpart (50.89) at the level of statistical significance of 0.01 (see table 5). Furthermore, it was decided to reject the same null hypothesis of seven variables of organizational change (18 variables) taken individually at the statistical significance level of 0.01 , according to the test of univariate $\mathrm{F}$ (see table 6).

\subsection{Organizational Commitment and Change}

The relationship between organizational commitment and change are investigated. The third hypothesis to be tested is:

\section{H3: There is no relationship between organizational change and organizational commitment at King Faisal Hospital in Al-Taif Governorate, KSA.}

According to the results of correlation coefficient, there is a statistically significant correlation between the aspects of organizational commitment and organizational change. The correlation of cognitive, affective and behavioral $(0.092,0.007$, and 0.300$)$ respectively was found to be significant at 0.05 level. The overall correlation is 0.571 .

Table 7. The relationship between organizational commitment and change

\begin{tabular}{llll}
\hline The Variables Of Organizational Commitment & Beta & $\mathbf{R}$ & $\mathbf{R}^{\mathbf{2}}$ \\
\hline Affective Commitment & $0.318^{* *}$ & 0.092 & 0.0423 \\
Continuance Commitment & $0.277^{* *}$ & 0.007 & 0.0119 \\
Normative Commitment & $0.230^{* *}$ & 0.300 & 0.1670 \\
\hline - Multiple Correlation Coefficients (MCC) & & 0.571 & \\
- Determination Coefficient (DC) & & 0.327 & \\
- The Value of Calculated F' & & 47.025 \\
- Degree of Freedom & & 3,291 \\
- The Value of Indexed F & & 3.78 \\
- Level of Significant & & 0.000 & \\
\hline$* * \mathrm{P}<.01$ & & & \\
\hline
\end{tabular}


Depending on MRA, Table 7 presents the type and strength of the relationship between organizational commitment and change. The findings of MRA include the following:

1) According to $\mathrm{MCC}$, there is a statistically significant relationship between organizational change and organizational commitment, $57 \%$.

2) Based on DC, organizational change may interpret 33\% of the total differentiation in organizational commitment.

3) On the basis of MRA, the variables of organizational change providing more explanation of the difference in the level of organizational commitment include the cognitive dimension (0.32), the affective dimension (0.27) and finally the behavioral dimension (0.23).

As a result, the null hypothesis is rejected and the alternative hypothesis is accepted. This is because the model of MRA has shown that there was fundamental relationship between organizational commitment and organizational change at the statistical significance level of 0.01 , according to T-Test (see Table 7).

\section{Research Findings}

1) The researcher was able to determine that organizational commitment is one of the important elements that have impact on organizational change. Organizational commitment is the most important determinant of attitudes toward organizational change. It plays an important role in employee's acceptance of change. It will result in willingness to accept organizational change. In sum, a greater degree of organizational commitment should lead to successful organizational readiness for a change process. An employees' acceptance of organizational change increases with organizational commitment. In other words, employees with high organizational commitment are more willing to exert more effort in a change project and, therefore, it is more likely to develop positive attitudes towards organizational change.

2) It has turned out that differences exist among the employees regarding their evaluative attitudes towards organizational commitment, most importantly "lack of work opportunities at other places is one of the most important reasons behind my remaining at this hospital", "this hospital deserves my full interest and loyalty", "I will not leave this hospital now as I feel I have duty towards its members", "I feel emotional relation to the hospital where I work", "I feel I am a member of the family of this hospital", "I think every person should keep his or her loyalty to the hospital", and "I feel strong loyalty and belonging to the family of this hospital".

3) It is revealed that differences exist among the employees regarding their evaluative attitudes towards organizational change, most importantly "I usually take advantage of the change in the hospital", "most of the changes in the hospital bother me", "I usually hesitate to try any new ideas in the hospital", "change in the work environment reduces my ability to control what is going on around me in the hospital", "I'm looking forward to the change happening in my field in the hospital", "I intend to do everything in my power to support change in the hospital", and "change usually benefits the hospital".

4) There is a statistically significant relationship between the dimensions of organizational commitment (the cognitive dimension, the affective dimension and the behavioral dimension) and organizational change at King Faisal Hospital in Al-Taif Governorate, KSA.

\section{Recommendations}

When a decision to apply organizational change occurs at King Faisal Hospital in Al-Taif Governorate, KSA, managers should pay attention to their communication approach with employees, employees' attitude, perception of managers' actions, employees' motivation and continuous improvement of the working environment. The following actions are suggested:

1) Managers should understand that different individuals hold dissimilar opinions about change. Also, not all employees are outspoken and willing to be honest with their managers. Therefore, managers should have the initiative to interact with employees and keep them informed about any organizational change. By maintaining communication and listening to employees, managers can understand their unfulfilled needs and resistance to change.

2) Managers should be able to understand employees' attitudes, but also they should keep in mind the stages of human cycle of negative response in hospitality industry, such as stability, immobilization and denial.

3) Managers should guide and direct employees along the organizational change process, be aware of importance of employees' motivation to proceed with change, and be receptive to new ideas that come from employees. 
4) Managers should continue to communicate with employees about the change implemented. This will promote an open exchange of ideas and information among all parties.

5) Managers can discover to what extent change affects employees and take corrective actions immediately to support them. For example, managers should be aware that organizational change may have positive results into the hospital but do not necessarily bring positive outcome to employees. Change of a working system may increase employees' income with extra workload creating fatigue and low spirits.

6) Decision- makers and officers-in-charge in regard to health service at the governmental sector in KSA in general and King Faisal Hospital in particular may make use of the findings of the present study so as to provide the suitable organizational environment that allows the creation of positive work conditions among all employees at the various administrative levels at the hospital. This will motivate them both materially and morally to promote positive effective behavioral attitudes that influence the process of organizational commitment of employees in the different units and administrative departments at the hospital.

7) It is necessary that those in charge of the hospital make use of the high level of organizational commitment among some employees and that they investigate reasons behind the decline of the levels of organizational commitment among some other employees so as to avoid them. Attention should be paid to planning and implementing a host of training programs that can raise the standard of organizational commitment of employees as this may contribute into the upgrading of the level of services provided by employees at the hospital.

8) The Personnel Department at the hospital should conduct periodic questionnaires so as to recognize the standard of organizational commitment and reasons behind it. Findings of this questionnaire should be the basis of a program aiming at raising the level of employees' organizational commitment.

9) Administrative leaders and employees should imbibe the concept of organizational commitment and its various components (affective, continuant, and normative) by training on true and varied experiences in the field of organizational commitment and deepening belief in the mission of the hospital, along with appreciation of its importance and role in providing health security for employees. Besides, awareness of the importance of organizational commitment and its role in realizing the goals of the hospital should be raised besides learning the experiences of foreign countries in this respect.

\section{Limitations and Future Research}

Several limitations of this study should be considered. First, the research population under study involves all categories of employees at King Faisal Hospital in Al-Taif Governorate, KSA. Also, the present study has drawn on the questionnaire method for collecting primary data necessary for the study. The questionnaire list is interested in recognizing organizational commitment and change.

There are several areas for possible future research. First, it will be useful to investigate the relationships between organizational change and organizational culture at larger organizations. Second, the longitudinal importance of the size of the hospital to the relationship between managers and employees when organizational change occurs should be studied. The research will be conducted in several cities in KSA to obtain a comparative analysis of attitude and behavior of employees and relevance of tested theories. Third, a comparative analysis between private and public hospitals may be made. This subject may be applied in different fields other than the health sector. Future researches also need to investigate the relationship between organizational change and burnout of employees. Finally, future studies need to examine the relationship between organizational cynicism and organizational change.

\section{Conclusion and Implications}

Managers may need to adopt one or more approaches to handle its organizational changes. A dominant culture in a given organization may not be as complex as the weak cultures, or sub-cultures in an organization. This poses a real challenge to managers in introducing changes considering the rapid development in the current business environment. Since change involves people, treating them is critical in addressing any change in the organization.

Organizational change implies departure from the normal situation and has implications on organizational policy. One implication is related to organizational leadership. In this study, the negative attitude toward change was not prevalent. This means that Saudi leaders have fewer problems in introducing organizational changes. Nonetheless, the task of handling change in an organization can be difficult if the organizational policy is not well communicated throughout the organization. Further, effective leaders have to guarantee that the proposed changes are accepted and committed by all members in the organization. Organizational reforms should not only be "top-down", but also "bottom-up" to guarantee its effectiveness in the long run. It also implies that managers have 
to revise organizational policies at an incremental pace, and patiently make improvements leading to the intended change in the organization.

There are several practical implications for managers and organizations facing organizational change. First, it was shown that good and effective work relationships are very important in organizational change. Handling conflicts, building supportive work relationships, and communicating effectively contribute to the creation of positive attitudes to change and, therefore, to the success of a change program. Second, organizations need to examine the extra workload which organizational change may create. Therefore, organizations need to plan the change carefully in order to create a well-structured work environment and a well-balanced work schedule to reduce stress and uncertainty.

There are some measures that can be taken. First, the more employees that are involved directly in the change process itself, the less they will make dispositional attributions because they are not to blame. Second, the less employees are surprised by management actions and the more they understand the reasons for these actions, the more they will see things from the management perspective. This will reduce the tendency to make dispositional attributions like blaming selfish or incompetent management. Third, past failures need to be fully explained rather than ignored. It may be true that the past cannot be undone, but it can have a strong influence on the present and future through the attributions made by employees. If past failure was attributable to management mistakes, it should be acknowledged in order to preserve credibility. Finally, it is important that management make serious efforts to see the situation from the lower level employees' perspective to understand why they tend to blame management.

\section{References}

Babbie, C. (1995). The Practice of Social Research. California: Wadsworth Publishing Company.

Bareil, C., Savoie, A., \& Meunier, S. (2007). Patterns of Discomfort with Organizational Change. Journal of Change Management, 7(1), 13-24. http://dx.doi.org/10.1080/14697010701232025

Bateman, T., \& Strasser, S. (1984). A longitudinal Analysis of the Antecedents of Organizational Commitment. Academy of Management Journal, 21, 95-112. http://dx.doi.org/10.2307/255959

Bernerth, J. (2004). Expanding Our Understanding of the Change Message. Human Resource Development Review, 3(1), 36-52. http://dx.doi.org/10.1177/1534484303261230

Bianey, C., Ulloa, R., \& Adams, S. (2004). Attitude Toward Teamwork and Effective Teaming. Team Performance Management, 10(7/8), 145-151. http://dx.doi.org/10.1108/13527590410569869

Bold, O. (2010). Basic Concepts of Change Management of SMEs. Journal of Advanced Research in Management, 1(2), 102-111.

Brewer, A. (1996). Developing Commitment Between Managers and Employees. Journal of Managerial Psychology, 11(4), 24-34. http://dx.doi.org/10.1108/02683949610117599

Cao, G., Clarke, S., \& Lehaney, B. (2000). A Systematic View of Organizational Change and TQM. The TQM Magazine, 12(3), 186-193. http://dx.doi.org/10.1108/09544780010320241

Carnall, C. A. (1990). Managing Change in Organizations, Prentice-Hall International (UK). Hemel Hempstead.

Darwish, Y. (2000). Organizational Commitment and Job Satisfaction as Predictors of Attitudes Toward Organizational Change in a Non-Western Setting. Personnel Review, 29, 6-25.

Dobrea, R., \& Găman, A. (2011). Aspects of the Correlation between Corporate Social Responsibility and Competitiveness of Organization, Revisit. Economic, Seria Management, 14(1), 236.

Dunham, R., Grube, J., Gardner, D., Cummings, L., \& Pierce, J. (1989). The Development of an Attitude Toward Change Instrument. Paper Presented at the Academy of Management Annual Meeting, Washington, DC.

Dupuy, F. (2002). The Chemistry of Change: Problems, Phases and Strategy. New York: Palgrave.

Elias, S. (2009). Employee Commitment in times of Change: Assessing the Importance of Attitudes towards $\begin{array}{llll}\text { Organizational Change. Journal of } & \text { Management, }\end{array}$ http://dx.doi.org/10.1177/0149206307308910

Elizur, D., \& Guttman, L. (1976). The Structure of Attitudes toward Work and Technological Change within an Organization. Administrative Science Quarterly, 21(1), 611-23. http://dx.doi.org/10.2307/2391719 
Freund, A., \& Carmeli, A. (2003). An Empirical Assessment: Reconstructed Model for Five Universal Forms of Work Commitment. Journal of Managerial Psychology, 18(7), 708-725. http://dx.doi.org/10.1108/02683940310502403

Greenberg, J., \& Baron, R. (2003). Behaviour in Organizations: Understanding and Managing the Human Side of work (8th ed.). Upper Saddle River: Pearson Education, Inc.

Guest, D. (1987). Human Resource Management and Industrial Relations. Journal of Management Studies, 24(5), 503-21. http://dx.doi.org/10.1111/j.1467-6486.1987.tb00460.x

Guest, D. (1997). Human Resource Management and Performance: A Review and Research Agenda. International Journal of Human Resource Management, 8(3), 263-276. http://dx.doi.org/10.1080/095851997341630

Hampel, P., Maris, S., \& Martinsons, G. (2009). Developing International Organizational Change Theory Using Cases From China. Human Relations, 62(4), 459-499. http://dx.doi.org/10.1177/0018726708101980

Hatch, T. (2009). Managing to Change: How schools can survive. Columbia University, New York: Teachers College.

Iverson, R. (1996). Employee Acceptance of Organizational Change: The Role of Organizational Commitment. The International Journal of Human Resource Management, 7(1), 122-49. http://dx.doi.org/10.1080/09585199600000121

Iverson, R., \& Roy, D. (1994). A Causal model of Behavioural Commitment: Evidence from a Study of Australian Blue-Collar Employees. Journal of Management, 20(1), 15-41. http://dx.doi.org/10.1177/014920639402000102

Jalonen, P., Virtanen, M., Vahtera, J., Elovainio, M., \& Kivimaki, M. (2006). Predictors of Sustained Organizational Commitment Among Nurses with Temporary Job Contracts. Journal of Nursing Administration, 36, 268-276. http://dx.doi.org/10.1097/00005110-200605000-00020

Jernigan, I., Beggs, J., \& Kohut, G. (2002). Dimensions of Work Satisfaction as Predictor of Commitment Type. Journal of Managerial Psychology, 17(7), 546-579. http://dx.doi.org/10.1108/02683940210444030

Joiner, T., \& Bakalis, S. (2006). The Antecedents of Organizational Commitment: The Case of Australian Casual Academics. International Journal of Educational Management, 20(6), 439-452. http://dx.doi.org/10.1108/09513540610683694

Juechter, W. M., Caroline, F., \& Alford, R. J. (1998). Five Conditions for High performance Cultures. Training and Development, 52(5), 63-7.

Kanter, R., Stein, B., \& Jick, T. (1992). The Challenge of Organizational Change. New York: The Free Press.

Lau, C., \& Woodman, R. (1995). Understanding Organizational Change: A Schematic Perspective. Academy of Management Journal, 38(2), 537-54. http://dx.doi.org/10.2307/256692

Lee, H. (2000). An Empirical Study of Organizational Justice as a Mediator of the Relationships among Leader-Member Exchange and Job Satisfaction, Organizational Commitment, and Turnover Intentions in the Lodging Industry. Doctoral dissertation, Virginia Polytechnic Institute and State. Retrieved from http://scholar.lib.vt.edu/theses.pdf

Linstone, H., \& Mitroff, I. (1994). The Challenges of the $21^{\text {st }}$ Century. New York: State University of New York Press.

Madsen, S., Miller, D., \& John, C. (2005). Readiness for Organizational Change: Do Organizational Commitment and Social Relationships in the Workplace Make a difference? Human Resource Development Quarterly, 16(2), 213-234. http://dx.doi.org/10.1002/hrdq.1134

Meyer, J., \& Allen N., (1997). Commitment in the Workplace: Theory, Research and Application. London: Sage.

Meyer, J., \& Allen, N. (1988). Links between Work Experience and Organizational Commitment: A Longitudinal Analysis. Journal of Occupational Psychology, 61, 195-209. http://dx.doi.org/10.1111/j.2044-8325.1988.tb00284.x

Meyer, J., \& Allen, N. (1991). A Three Component Conceptualization of Organizational Commitment. Human Resource Management Review, 11(1), 61-89. http://dx.doi.org/10.1016/1053-4822(91)90011-Z 
Meyer, J., Allen, N., \& Smith, C. (1993). Commitment to Organizations and Occupations: Extension and Test of a Three-Component Conceptualization. Journal of Applied Psychology, 78(4), 538-551. http://dx.doi.org/10.1037/0021-9010.78.4.538

Mowday, R., \& Spencer, D. (1981). The Influence of Task and Personality Characteristics of Employee Turnover and Absenteeism. Academy of Management Journal, 24, 634-642. http://dx.doi.org/10.2307/255582

Mowday, R., Porter, L., \& Steers, R. (1982). Employee-Organization linkages: The Psychology of Commitment, Absenteeism, and Turnover. New York: Academic Press.

Mowday, R., Steers, R., \& Porter, L. (1979). The Measurement of Organizational Commitment. Journal of Vocational Behavior, 14(3), 224-247. http://dx.doi.org/10.1016/0001-8791(79)90072-1

Mueller, C., Wallace, J., \& Price, J. (1992). Employee Commitment: Resolving Some Issues. Work and Occupations, 19(3), 211-236. http://dx.doi.org/10.1177/0730888492019003001

Nunnally, J., \& Bernstein, I. (1994). Psychometric Theory. New York: McGraw-Hill.

Pettigrew, A., Woodman, R., \& Cameron, K. (2001). Studying Organizational Change and Development: Challenges for Future Research. Academy of Management Journal, 44(4), 697-713. http://dx.doi.org/10.2307/3069411

Porter, L., Crampon, W., \& Smith, F. (1976). Organizational Commitment and Managerial Turnover: A Longitudinal Study. Organizational Behaviour and Human Performance, 15(1), 87-98. http://dx.doi.org/10.1016/0030-5073(76)90030-1

Porter, L., Steers, R., Mowday, R., \& Boulian, P. (1974). Organizational Commitment, Job Satisfaction, and Turnover among Psychiatric Technicians. Journal of Applied Psychology, 59(5), 603-609. http://dx.doi.org/10.1037/h0037335

Price, J. L. (1997). Handbook of Organizational Measurement. Bradford, UK: MCB University Press.

Radu, C., \& Năstase, M. (2011). Leadership and Gender Differentiation. Review of International Comparative Management, 12(3), 455.

Rafferty, A., \& Simons, R. (2006). An Examination of the Antecedents of Readiness for Fine-Tuning and Corporate Transformation Changes. Journal of Business and Psychology, 20(3), 325-350. http://dx.doi.org/10.1007/s10869-005-9013-2

Raju, P., \& Srivastava, R. (1994). Factors Contributing to Commitment to the Teaching Profession. International Journal of Educational Management, 8(5), 7-13. http://dx.doi.org/10.1108/09513549410065684

Sharma, J., \& Bajpai. N. (2010). Organizational Commitment and its Impact on Job Satisfaction of Employees: A Comparative Study in Public and Private Sector in India. International Bulletin of Business Administration, 9, 7-19.

Silverthorne, C. (2004). The Impact of Organizational Culture and Person Organization Fit on Organizational Commitment and Job Satisfaction in Taiwan. The Leadership and Organization Development Journal, 25(7), 522-599. http://dx.doi.org/10.1108/01437730410561477

Somers, M. (1995). Organizational Commitment, Turnover and Absenteeism: An Examination of Direct and Interaction Effects. Journal of Organizational Behavior, 16, 49-58. http://dx.doi.org/10.1002/job.4030160107

Soparnot, R. (2011). The Concept of Organizational Change Capacity. Journal of Organizational Change Management, 24(5), 640-661. http://dx.doi.org/10.1108/09534811111158903

Steers, R. (1977). Antecedents and Outcomes of Organizational Commitment. Administrative Science Quarterly, 22(1), 46-56. http://dx.doi.org/10.2307/2391745

Visagie, C. (2010). The Relationship between Employee Attitudes towards Planned Organizational Change and Organizational Commitment: An Investigation of a Selected Case within the South African Telecommunications Industry. A Thesis Presented to the Cape Peninsula University of Technology, in Partial Fulfillment of the Requirements for the Master of Technology.

Wagner, C. (2007). Organizational Commitment as a Predictor Variable in Nursing Turnover Research:

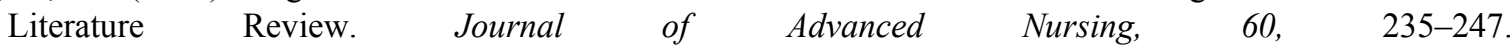
http://dx.doi.org/10.1111/j.1365-2648.2007.04421.x 
Wasti, S. (2003). Organizational Commitment, Turnover Intentions and the Influence of Cultural Values. Journal of Occupational and Organizational Psychology, 76(3), 303-321. http://dx.doi.org/10.1348/096317903769647193

Weber, P., \& Weber, J. (2001). Changes in Employee Perceptions During Organizational Change. Leadership and Organization Development Journal, 22(6), 291-300. http://dx.doi.org/10.1108/01437730110403222

Yousef, D. (2000). Organizational Commitment as a Mediator of the Relationship between Islamic Work Ethic and Attitudes toward Organizational Change. Human Relations, 53(4), 513-572. http://dx.doi.org/10.1177/0018726700534003

\section{Copyrights}

Copyright for this article is retained by the author(s), with first publication rights granted to the journal.

This is an open-access article distributed under the terms and conditions of the Creative Commons Attribution license (http://creativecommons.org/licenses/by/3.0/). 